\title{
Multi-Parameter Monitoring Menggunakan Jaringan Sensor Wireless untuk Aplikasi Monitoring dan Database Medis
}

\author{
Beryl Abdiel Sahata Ebenezer Sitorus, Rachmad Setiawan, dan Nada Fitrieyatul Hikmah \\ Departemen Teknik Biomedik, Institut Teknologi Sepuluh Nopember (ITS) \\ e-mail:rachmad@ee.its.ac.id
}

\begin{abstract}
Abstrak-Healthcare Monitoring merupakan teknologi monitoring yang dikhususkan untuk memantau kondisi vital sign pada pasien. Monitoring yang dilakukan adalah memantau vital sign pada pasien. Penggunaan komunikasi wireless ini difungsikan untuk meningkatkan aksesibilitas dari monitoring itu sendiri dengan menggunakan komunikasi wireless, data monitoring dapat dilihat lebih mudah dan dapat diakses diluar dari ruang rawat inap pasien. Pada penelitian ini monitoring yang dipantau berjumlah tiga parameter. yang disebut multiparameter monitoring. Jenis sensor yang digunakan adalah weight scale sensor yang berfungsi untuk memantau berat infus, pulse sensor yang berfungsi untuk memantau heart rate pada pasien, dan temperature sensor yang berfungsi untuk memantau temperature tubuh pasien. Multi-parameter monitoring akan dihubungkan dengan mikrokontroler untuk dapat mengirimkan data secara wireless, maka dari itu dibuatlah aplikasi dan database medis yang difungsikan untuk menyimpan data ruangan, melakukan manajemen ruangan pada rumah sakit, dan menangkap data yang dikirim oleh mikrokontroler secara wireless yang dapat ditampilkan pada aplikasi medis. Berdasarkan hasil penelitian didapatkan sebuah aplikasi manajemen ruangan yang sudah terkoneksi dengan database yang dapat diubah untuk menyesuaikan ruangan yang ada di rumah sakit dan aplikasi ini dapat membuat report harian yang berisikan tentang data setiap sensor sesuai dengan tanggal yang diinginkan.
\end{abstract}

Kata Kunci-Database, Monitoring, Pulse Sensor, Temperature Sensor, Vital Sign, Weight Scale Sensor, Wireless.

\section{PENDAHULUAN}

$\mathrm{T}$ EKNOLOGI dari tahun ke tahun semakin berkembang. Salah satunya adalah teknologi dalam bidang kesehatan, banyak sekali teknologi yang sudah berkembang dalam bidang kesehatan, salah satunya adalah teknologi monitoring pada pasien yang biasanya digunakan untuk mengetahui kondisi kesehatan pasien [1]. Perkembangan teknologi komunikasi sudah mulai menuju pada Internet of Things (IoT), yaitu sebuah konsep di mana suatu objek yang memiliki kemampuan untuk mentransfer data melalui jaringan tanpa memerlukan interaksi pasien ke pasien atau pasien ke komputer. IoT telah berkembang dari konvergensi teknologi wireless Pada saat melakukan monitoring terdapat beberapa metode yang dapat dilakukan, salah satunya dengan menggunakan teknologi Wireless Sensor Network (WSN). Teknologi Wireless Sensor Network adalah suatu sistem embedded yang di dalamnya terdapat satu atau lebih sensor yang dilengkapi dengan peralatan sistem komunikasi [2]. Healthcare selalu menjadi perhatian besar bagi dunia karena menyangkut kualitas hidup yang dapat dimiliki seorang individu. Selalu lebih baik untuk mencegah penyakit daripada mengobatinya, sehingga dibutuhkanlah monitoring kesehatan secara berkala, Healthcare monitoring dilakukan secara berkala. Maka dari itu perkembangan healthcare monitoring yang awalnya masih menggunakan kabel, sekarang sudah mulai dikembangkan untuk menggunakan wireless, digunakanlah wireless sensor networks untuk menghasilkan healthcare monitoring secara wireless [3]. Wireless sensor networks terdiri dari banyak perangkat otonom yang terdistribusi secara spasial, maka dari itu wireless sensor networks disebut dengan smart sensor nodes yang dapat melakukan monitoring lingkungan atau fisik di lokasi yang berbeda. Wireless sensor networks memiliki kemampuan komunikasi, modul pemrosesan dengan memori, memiliki fungsi sensing dan modul daya yang membuat dapat beroperasi secara otonom. Dengan begitu wireless sensor networks sangat tepat untuk digunakan pada healthcare application [4].

Teknologi monitoring pada bidang kesehatan tertuju pada bagian vital sign pasien yang paling penting untuk dimonitor. Vital sign adalah ukuran statistik berbagai fisiologis yang digunakan untuk membantu menentukan kondisi kesehatan seseorang, terutama pada pasien yang secara medis tidak stabil atau memiliki faktor-faktor resiko komplikasi kardiopulmonal dan untuk menilai respon terhadap intervensi. Terdapat 8 vital sign yang penting untuk di monitoring yaitu temperature tubuh, pulse, tekanan darah, $\mathrm{SpO} 2$, urine, pain, tingkat pernapasan, level of consciousness [5].

Berdasarkan beberapa vital sign dibuatlah sebuah alat monitoring yang berfungsi untuk memantau setiap keadaan dari vital sign yang ada pada pasien. Pemantauan vital sign pada pasien bertujuan untuk mengetahui kondisi pasien setiap saat, dengan adanya vital sign monitoring perawat dan dokter dapat langsung mengambil tindakan. Oleh karena itu vital sign monitoring sangatlah penting dalam dunia healthcare [6]. Berdasarkan perkembangan monitoring pada bidang healthcare, sistem database sudah mulai digunakan dalam bidang healthcare, penggunaan database ditujukan untuk menyimpan data rekam medis pasien. Penggunaan database pada monitoring healthcare sangatlah penting karena dengan menggunakan sistem database rumah sakit, menyimpan semua data pasien seperti histori kesehatan pasien, registrasi pasien, sampai histori obat yang digunakan oleh pasien dapat disimpan pada database akhirnya dari 


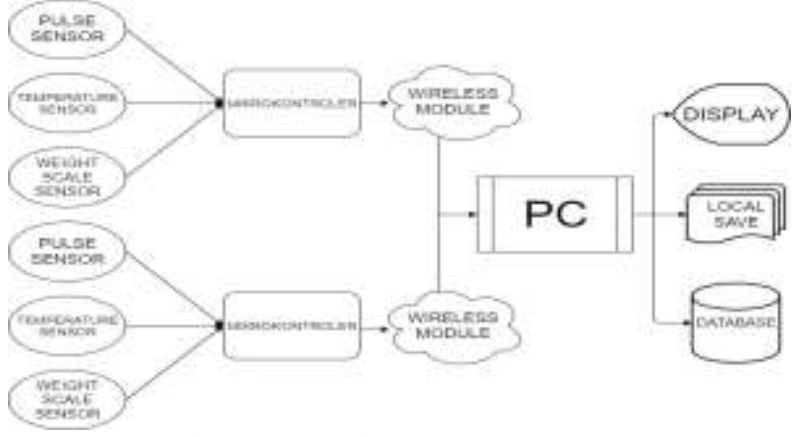

Gambar 1. Gambaran Umum Sistem

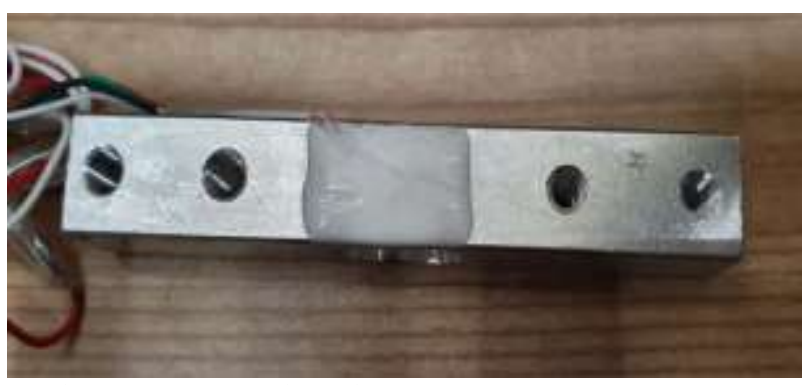

Gambar 2. Sensor Weight Scale

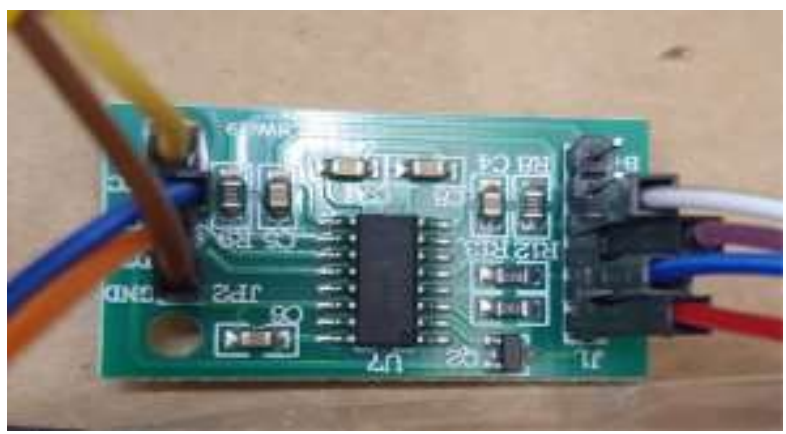

Gambar 3. HX711

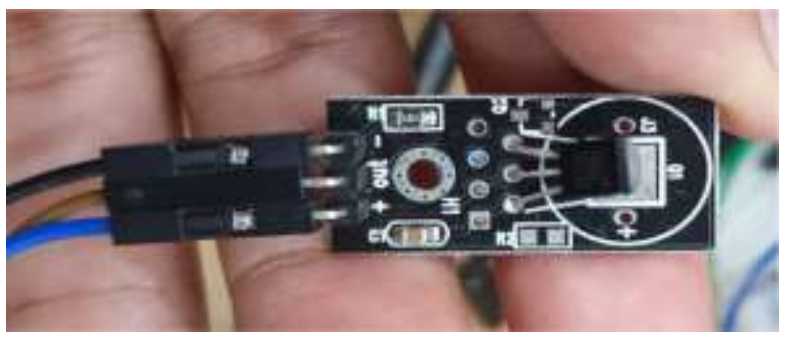

Gambar 4. Sensor Temperature DS18B20

sinilah data vital sign monitoring sangat penting untuk disimpan pada database. Data vital sign yang simpan dapat digunakan sebagai referensi kesehatan pasien yang sedang dirawat intensif di rumah sakit [3].

\section{PERANCANGAN SISTEM}

\section{A. Gambaran Umum Cara Kerja Sistem}

Sistem monitoring pada penelitian ini diimplementasikan dalam bahasa pemograman arduino IDE pada mikrokontroler, menggunakan bahasa PHP pada aplikasi dan menggunakan Relational Database Manajemen Sistem MySQL [7]. Secara garis besar sistem monitoring yang dibuat digambarkan oleh Gambar (1). Pada bagian pertama merupakan bagian sensor, parameter sensor yang digunakan pada setiap ruangan berjumlah tiga yaitu pulse sensor, weight scale sensor, dan temperature sensor. Tiga parameter

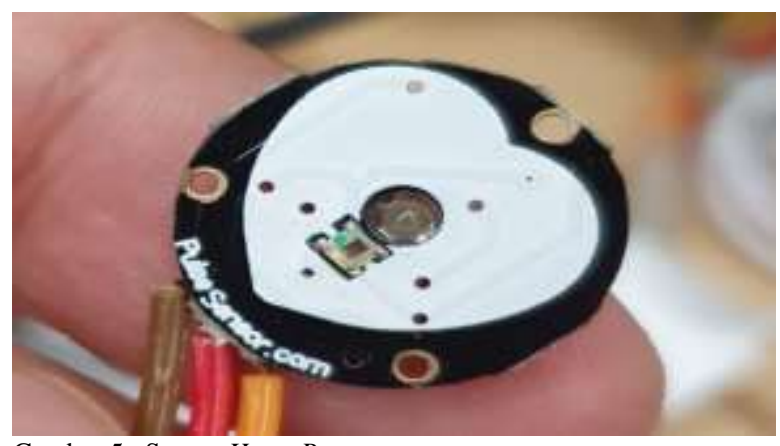

Gambar 5. Sensor Heart Rate

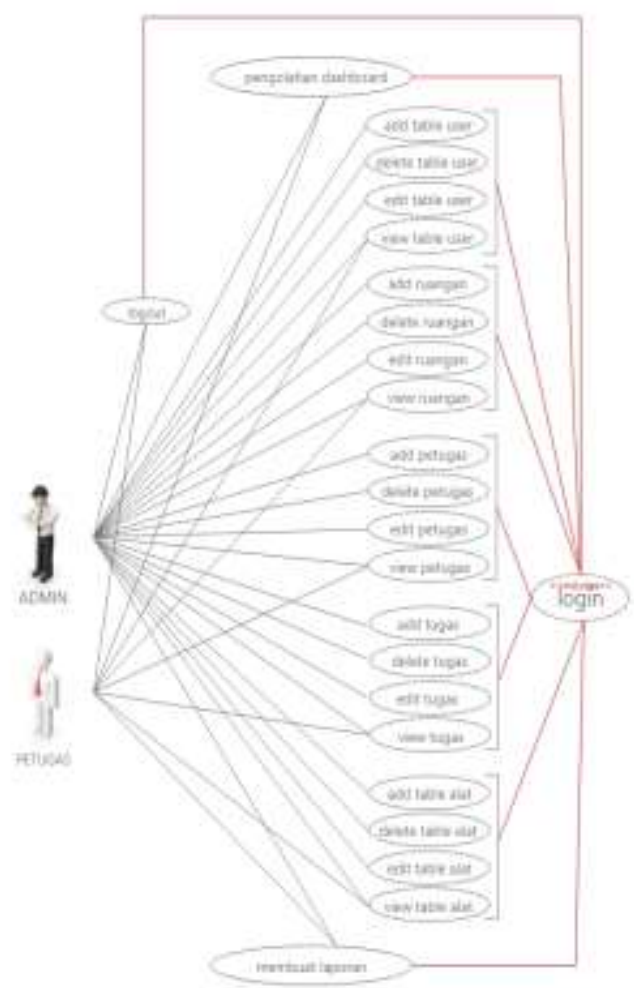

Gambar 6. Use Case Pada Aplikasi.

sensor ini dihubungkan dengan satu mikrokontroler. Satu mikrokontroler merepresentasikan suatu ruangan pada rumah sakit. Jadi, pada blok pertama terlihat pada Gambar (1) terdapat enam buah sensor dan dua mikrokontroler, maka dapat diketahui bahwa bagian pertama menggambarkan jumlah sensor yang digunakan pada setiap ruangan. Pada bagian kedua merupakan gambaran proses komunikasi yang dilakukan oleh mikrokontroler, data yang diterima pada mikrokontroler akan dikirimkan secara wireless dengan menggunakan wireless module yaitu ESP8266 yang nantinya diterima oleh komputer. Proses penerimaan data pada mikrokontroler dengan komputer menggunakan IP address untuk dapat membedakan wireless module ruang satu dengan wireless module ruang lainnya. Setelah itu masuk pada bagian ketiga, pada bagian ketiga menjelaskan mengenai fungsi dari aplikasi yang dibangun untuk monitoring ini yaitu display, local save dan database. Display yang dimaksud adalah aplikasi dapat menampilkan data setiap parameter sensor yang dikirim oleh 

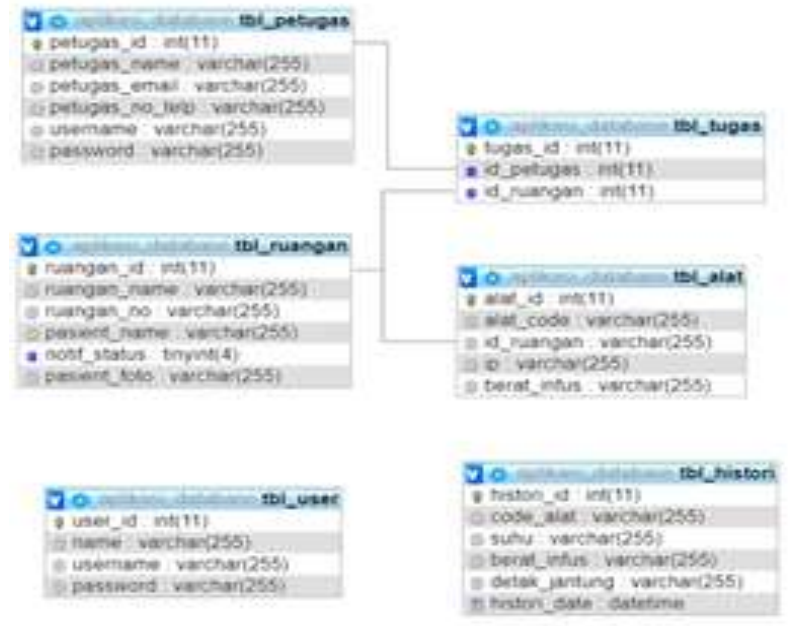

Gambar 7. Rancangan Database

Source: Ip 127.22.322

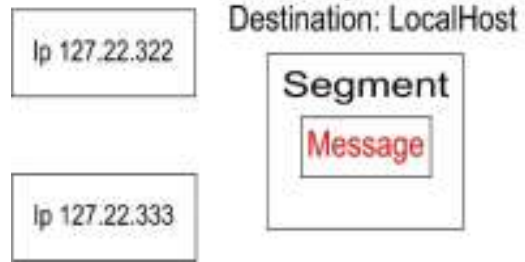

Gambar 8. Rancangan Transport Sender

\section{Source: Ip 127.22.322 Destination: LocalHost}
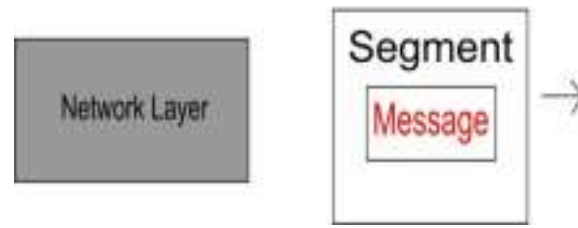

LocalHost

Gambar 9. Rancangan Transport Reciever

mikrokontroler secara real-time pada komputer. Local save yaitu memiliki fungsi untuk menyimpan data monitoring pada sebuah file report yang disimpan pada local drive yang ada di komputer. Database pada aplikasi difungsikan untuk melakukan manajemen ruangan agar pengiriman data dapat berlangsung dengan baik dan tidak terjadi duplikasi data, database juga difungsikan untuk menyimpan histori dari data monitoring per-harinya agar dapat dibuat suatu file report.

\section{B. Sensor}

Sensor yang digunakan pada penelitian ini berjumlah tiga sensor, penggunaan sensor dipenelitian ini sudah berbentuk modul yang siap dipakai. Sensor yang digunakan yaitu:

\section{1) Sensor Infus (Weight Scale)}

Sensor infus memiliki fungsi untuk mengukur berat infus secara continuous, pengukuran secara continuous dilakukan untuk mengetahui berat infus pada awal baru digunakan sampai akhirnya infus harus segera digantikan. Sensor yang digunakan adalah sensor weight scale sensor yang dihubungkan dengan HX711 dapat dilihat pada Gambar 3. HX711 adalah modul timbangan, yang memiliki prinsip kerja mengkonversi perubahan yang terukur dalam perubahan resistansi dan mengkonversinya ke dalam besaran tegangan melalui rangkaian yang ada. Hasil pengukuran sensor digunakan untuk mengetahui kondisi isi pada
Tabel 1.

Use Case Login

\begin{tabular}{|c|c|c|}
\hline Uji & Respon & Kesimpulan \\
\hline $\begin{array}{c}\text { Login } \\
\text { (Admin) }\end{array}$ & $\begin{array}{l}\text { Masuk kedalam aplikasi sebagai } \\
\text { Admin }\end{array}$ & Sesuai \\
\hline $\begin{array}{c}\text { Login } \\
\text { (Petugas) }\end{array}$ & $\begin{array}{l}\text { Masuk kedalam aplikasi sebagai } \\
\text { Petugas }\end{array}$ & Sesuai \\
\hline \multicolumn{3}{|c|}{$\begin{array}{c}\text { Tabel } 2 . \\
\text { Use Case User }\end{array}$} \\
\hline Uji & Respon & Kesimpulan \\
\hline $\begin{array}{c}\text { User } \\
\text { (Database) }\end{array}$ & $\begin{array}{c}\text { Halaman aplikasi memperlihatkan } \\
\text { database user }\end{array}$ & Sesuai \\
\hline $\begin{array}{c}\text { User } \\
\text { (Add } \\
\text { Form) }\end{array}$ & Form pengisian user database & Sesuai \\
\hline $\begin{array}{c}\text { User } \\
\text { (Update }) \\
\end{array}$ & Database terupdate setelah add form & Sesuai \\
\hline \multicolumn{3}{|c|}{$\begin{array}{c}\text { Tabel } 3 . \\
\text { Use Case Ruangan }\end{array}$} \\
\hline Uji & Respon & Kesimpulan \\
\hline $\begin{array}{l}\text { Ruangan } \\
\text { (Database) }\end{array}$ & $\begin{array}{c}\text { Halaman aplikasi memperlihatkan } \\
\text { database ruangan }\end{array}$ & Sesuai \\
\hline $\begin{array}{c}\text { Ruangan } \\
\text { (Add } \\
\text { Form) }\end{array}$ & Form pengisian ruangan database & Sesuai \\
\hline $\begin{array}{l}\text { Ruangan } \\
\text { (Update) }\end{array}$ & Database terupdate setelah add form & Sesuai \\
\hline
\end{tabular}

infusagar pada saat isi infus habis dapat langsung digantikan dapat dilihat pada Gambar 2.

\section{2) Sensor Temperature}

Sensor temperature memiliki fungsi untuk mengukur berat infus secara continuous, pengukuran suhu disini adalah pengukuran suhu tubuh agar dapat dimonitoring setiap harinya. Modul yang digunakan adalah modul DS18B20, modul DS18B20 ini adalah jenis sensor yang berfungsi untuk mengukur suhu dari $-55^{\circ} \mathrm{C}$ sampai $125^{\circ} \mathrm{C}$ dengan tingkat keakurasian $\left(+/-0.5^{\circ} \mathrm{C}\right)$ dan dengan resolusi $9-12$ bit dapat dilihat pada Gambar 4.

\section{3) Sensor Heart rate}

Sensor Heart rate memiliki fungsi untuk membaca atau mengukur tekanan darah dapat dilihat pada Gambar 5. Modul yang digunakan adalah modul AK90, pulse heart rate sensor adalah sebuah sensor denyut jantung. Sensor ini dapat mendeteksi denyut nadi pada jari telunjuk tangan dengan cara menggabungkan data denyut nadi dari sensor dengan program di mikrokontroler bisa di dapatkan nilai bpm, Heart rate sendiri merupakan detak jantung per satuan waktu yang biasanya dinyatakan dalam beats per menit (bpm).

\section{Perancangan Use Case Diagram}

Penggunaan sistem serta fungsi-fungsi yang dapat dikerjakan oleh masing-masing pengguna akan digambarkan dengan use case diagram dapat dilihat pada Gambar 6, definisi dari setiap use case adalah sebagai berikut; (1)Use Case Login / Sign in. Use case login dilakukan oleh setiap pengguna yang sudah didaftarkan oleh admin untuk masuk kedalam sistem; (2)Use Case Log Out. Use case Log Out digunakan oleh pengguna yang ingin keluar dari sistem; (3)Use Case Dashboard. Use case dashboard adalah 
Tabel 4.

Use Case Petugas

\begin{tabular}{ccc}
\hline \hline Uji & Respon & Kesimpulan \\
\hline Petugas & Halaman aplikasi memperlihatkan & Sesuai \\
(Database & database petugas & \\
) & & \\
Petugas & Form pengisian petugas database & Sesuai \\
$($ Add & & \\
Form $)$ & & \\
Petugas & Database terupdate setelah add form & Sesuai \\
$($ Update $)$ & & \\
\hline \hline
\end{tabular}

Tabel 5 .

Use Case Tugas

\begin{tabular}{|c|c|c|}
\hline Uji & Respon & Kesimpulan \\
\hline $\begin{array}{c}\text { Tugas } \\
\text { (Database } \\
\text { ) }\end{array}$ & $\begin{array}{c}\text { Halaman aplikasi memperlihatkan } \\
\text { database Tugas }\end{array}$ & Sesuai \\
\hline $\begin{array}{l}\text { Tugas } \\
\text { (Add } \\
\text { Form) }\end{array}$ & Form pengisian Tugas database & Sesuai \\
\hline $\begin{array}{l}\text { Tugas } \\
\text { (Update) } \\
\end{array}$ & Database terupdate setelah add form & Sesuai \\
\hline \multicolumn{3}{|c|}{$\begin{array}{c}\text { Tabel } 6 . \\
\text { Use Case Alat } \\
\end{array}$} \\
\hline $\mathrm{Uji}$ & Respon & Kesimpulan \\
\hline $\begin{array}{c}\text { Alat } \\
\text { (Database } \\
\text { ) }\end{array}$ & $\begin{array}{l}\text { Halaman aplikasi memperlihatkan } \\
\text { database Alat }\end{array}$ & Sesuai \\
\hline $\begin{array}{c}\text { Alat } \\
\text { (Add } \\
\text { Form) }\end{array}$ & Form pengisian Alat database & Sesuai \\
\hline $\begin{array}{c}\text { Alat } \\
\text { (Update) }\end{array}$ & Database terupdate setelah add form & Sesuai \\
\hline
\end{tabular}

interface yang menampilkan berbagai data inti seperti data dari sensor monitoring yang di tampilkan dalam bentuk graph dan data ruang serta informasi pasien pada ruang tersebut; (4)Use Case User. Use case User merupakan sebuah interface yang berfungsi untuk mendaftarkan level user dan melakukan registrasi user, di dalam interface ini terdapat database yang berisikan user-user yang dapat login pada aplikasi ini; (5)Use Case Ruangan. Use case Ruangan merupakan tempat registrasi database ruangan yang di dalamnya akan ada informasi mengenai nomer ruangan dan pasien yang dirawat diruang tersebut; (6)Use Case Tugas. Use case Tugas merupakan database yang menyimpan data mengenai petugas dan nomer ruang dengan database ini kita dapat mengetahui nama petugas yang sedang bertanggung jawab pada ruang yang aktif; (7)Use Case Alat. Use case Alat merupakan tempat database yang berfungsi untuk meregistrasi alat pada setiap ruangan yang mau digunakan, dengan database ini maka setiap alat memiliki nomer ruang masing-masing. Setiap alat dibedakan dengan nomer IP address; (8)Use Case Laporan. Use case Laporan merupakan bagian dari aplikasi yang bertugas untuk membuat sebuah laporan monitoring secara otomatis yang berfungsi untuk mempermudah user mendapatkan data monitoring dari pasien.

\section{Perancangan Database}

Perancangan database adalah proses untuk menentukan isi dan pengaturan data yang dibutuhkan untuk mendukung berbagai rancangan system dapat dilihat pada Gambar 7 . Rancangan Transport Sender dan Reciever dapat dilihat

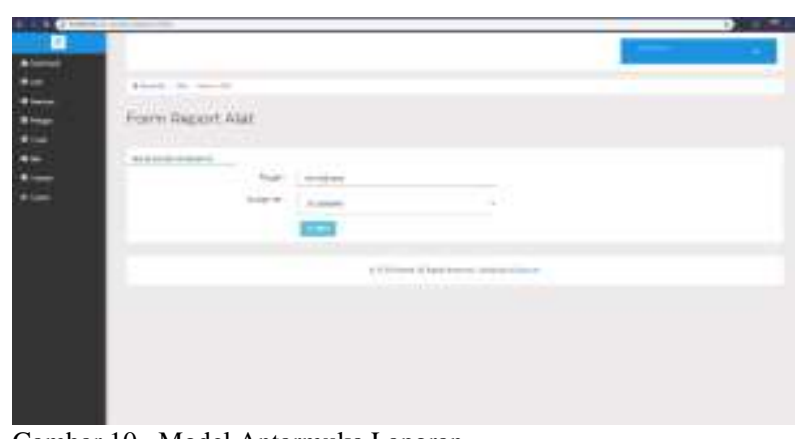

Gambar 10. Model Antarmuka Laporan

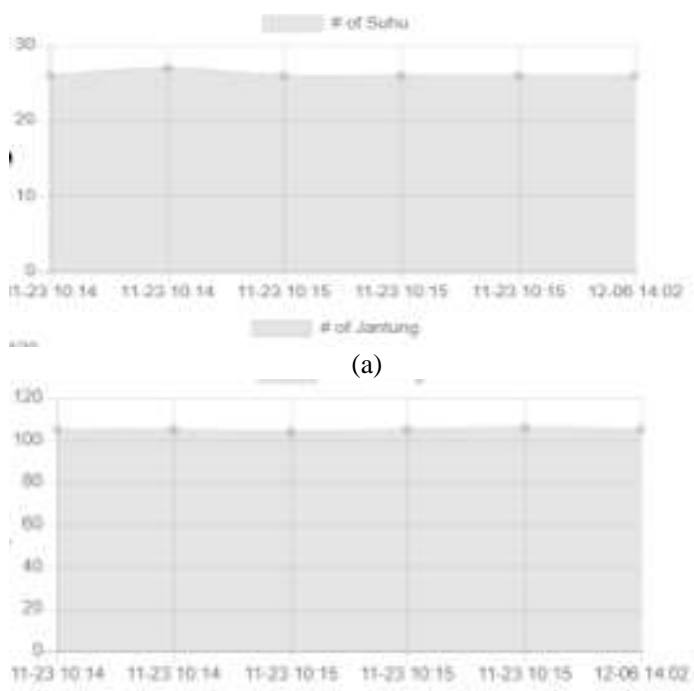

(b)

Gambar 11. Data Temperature Sensor (a), Data Pulse Sensor (b)

pada Gambar 8 dan Gambar 9.Berdasarkan sistem yang telah dibuat terdapat 6 tabel yang digunakan pada sistem wireless monitoring ini. Perancangan database berfokus pada interface yang dibuat dalam aplikasi monitoring dan fungsionalitas sistem. Tabel yang akan diimplementasikan adalah tbl_user, tbl_ruangan, tbl_alat, tbl_petugas, tbl_histori dan tbl_tugas.

Tabel tbl_user memuat informasi mengenai data dari user yang memiliki tingkatan admin pada aplikasi dan digunakan untuk data pengguna yang dapat login pada aplikasi. Tingkatan admin adalah user yang memiliki akses ke seluruh bagian dari aplikasi. Tabel tbl_ruangan memuat informasi mengenai data ruangan, di dalam tabel ruangan terdapat data mengenai nomer ruang, nama ruang dan nama pasien. Tabel tbl_petugas memuat informasi mengenai pengguna yang merupakan petugas atau perawat yang bertanggung jawab dengan pasien yang sedang dirawat disebuah ruangan dan tabel ini berfungsi untuk membuat akses login dengan tingkatan petugas yang hanya dapat melakukan monitoring di aplikasi. Tabel tbl_histori memuat informasi setiap data monitoring yang nantinya difungsikan untuk membuat laporan otomatis yang dapat memudahkan rumah sakit. Tabel tbl_alat memuat informasi mikrokontroler di dalam tabel ini data yang dimasukan adalah id alat, nama alat, $I P$ address alat dan id_ruangan. Tabel tbl_tugas memuat informasi berupa nama petugas dan nomer ruangan yang 


\begin{tabular}{cccccc}
\multicolumn{8}{c}{ Tanggal 2019-11-23 } \\
No & Alat & Ruangan & Suhu & Berat & Detak Jantung \\
1 & MWR & Mawar & $26 \mathrm{C}$ & $1000 \mathrm{Gr}$ & $105 \mathrm{Bpm}$ \\
2 & MWR & Mawar & $27 \mathrm{C}$ & $1000 \mathrm{Gr}$ & $105 \mathrm{Bpm}$ \\
3 & MWR & Mawar & $26 \mathrm{C}$ & $999 \mathrm{Gr}$ & $104 \mathrm{Bpm}$ \\
4 & MWR & Nawar & $26 \mathrm{C}$ & $999 \mathrm{Gr}$ & $105 \mathrm{Bpm}$ \\
5 & MWR & Mawar & $26 \mathrm{C}$ & $998 \mathrm{Gr}$ & $106 \mathrm{Bpm}$ \\
6 & MWR & Mawar & $26 \mathrm{C}$ & $998 \mathrm{Gr}$ & $105 \mathrm{Bpm}$
\end{tabular}

Gambar 12. Hasil Laporan Otomatis

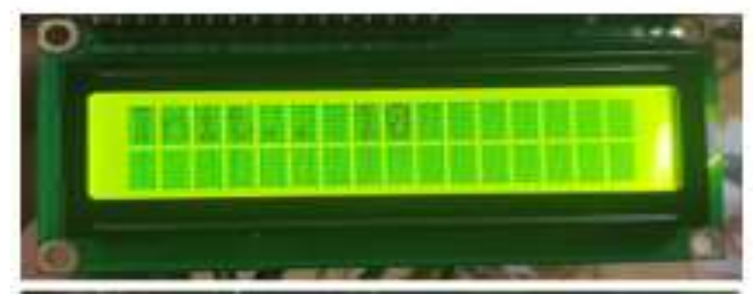

(a)

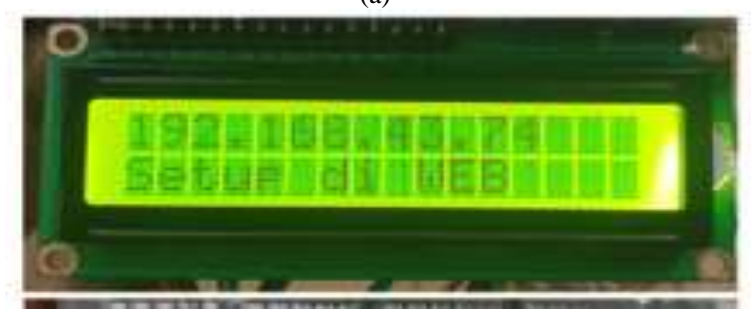

(b)

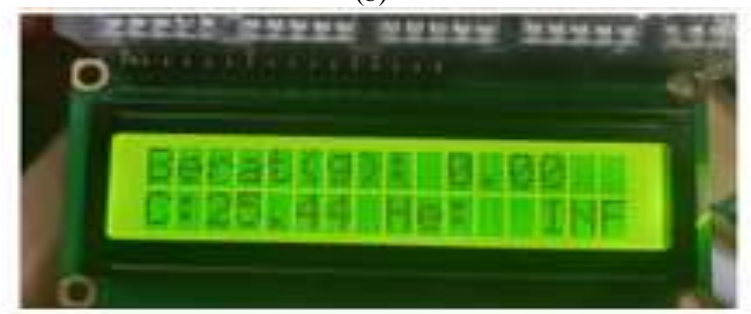

(c)

Gambar 13. Inisiasi komunikasi dengan WiFi (a), Display IP Address Mikrokontroler (b), Display Data Setiap Parameter Sensor (c)

fungsinya untuk mengetahui siapa petugas yang bertanggung atas ruangan tersebut.

\section{E. Perancangan Komunikasi}

Perancangan komunikasi antara lain sebagai berikut: (a) Application. Perancangan komunikasi disini pertama pada aplication menggunakan HTTP (hyperText Transfer Protocol, penggunaan HTTP dapat dicontohkan seperti jika pada saat memasukan IP localhost pada address bar yang ada di browser (client), HTTP akan mengirimkan HTTP GET yang merupakan sebuah request pada server. Server memproses request yang dikirim HTTP dan merespon dengan menampilkan halaman web yang direquest tersebut; (b)Transport . Pada bagian transport digunakan TCP (Transmission Control Protocol/Internet Protocol) penggunaan TCP pada bagian sender dapat dilihat di Gambar 11, pada gambar tersebut dimisalkan terdapat 2 alat yang berbeda keduanya memiliki IP address yang berbeda IP address itu adalah source setiap alat agar nantinya reciever mengetahui source dari data tersebut dari IP address. Digambarkan jika salah satu port mengirimkan data, data tersebut dibalut di dalam sebuah segment yang di

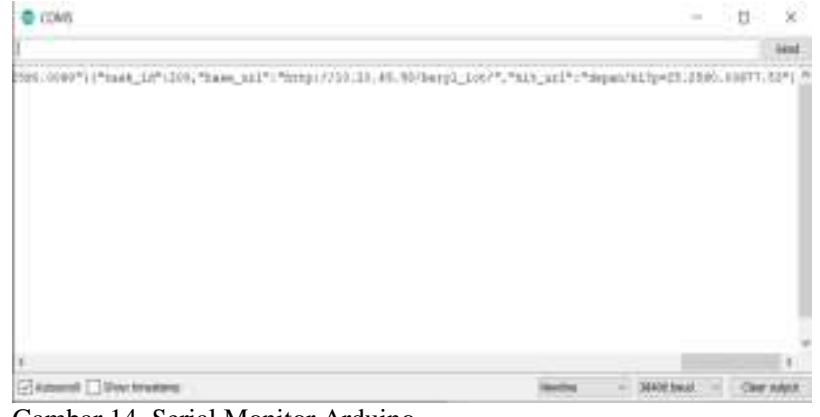

Gambar 14. Serial Monitor Arduino

\begin{tabular}{|c|c|c|c|c|c|c|}
\hline$-T$ & $\tau$ tisni if & , 1 it ilat & 1 sebs & beat its & detxijutux & Leni the \\
\hline 1. fluah jesain AHthps & & 2bt & 4259 & $10 \pi$ & 58 & 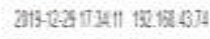 \\
\hline 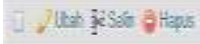 & & at & 4253 & $\mathrm{~m}$ & $58 \%$ & ज्ञा 121043 \\
\hline 1. Jubat josih a Haps & & 25 & - 2531 & 1x & ऊक्ष & 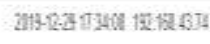 \\
\hline (1) Jihan jeSalt \& Hans & & 28 & $425 \pi$ & 10 & sूes & 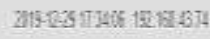 \\
\hline 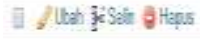 & & 20 & +283 & 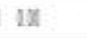 & 585 & 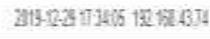 \\
\hline 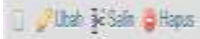 & & 35. & 4 zal & IX & 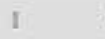 & 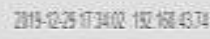 \\
\hline 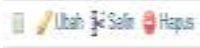 & & ZE & 424 & in & 1 & $219-2.27340$ 12.13674 \\
\hline Jithoh jeseh a Haps & & 24 & 4.253 & ix & t & 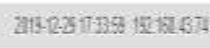 \\
\hline 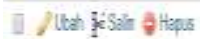 & & 24 & 4253 & $10 x$ & I & 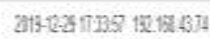 \\
\hline
\end{tabular}

Gambar 15. Updated Database

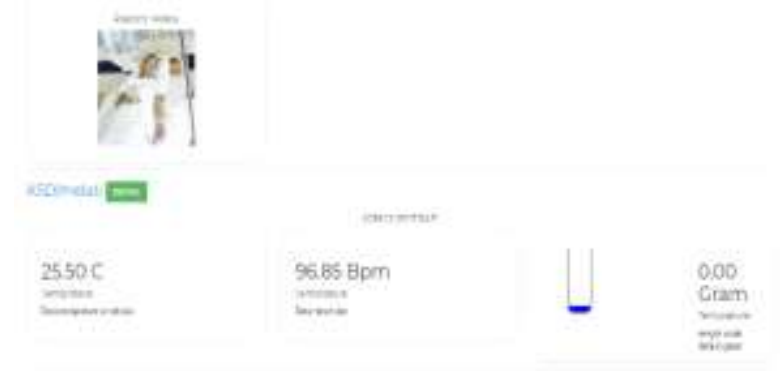

Gambar 16. Dashboard Aplikasi

dalamnya terdapat informasi source data dan destination data. Pada bagian reciever dapat dilihat pada Gambar 12, terlihat data yang sudah dibalut di dalam segment akan masuk ke destination yang dituju oleh data tersebut; (c)Network. Penggunaannya adalah untuk pemberi tanda pada setiap alat jadi data yang dikirim oleh alat A dan alat B dapat dibedakan, pembedanya adalah IP address dari setiap alat tersebut dengan begitu localhost dapat membedakan setiap alatnya, yang dimaksud dari membedakan adalah alat A akan masuk pada id alat 1 pada localhost dan alat B akan masuk pada id alat 2. Maka dari itu data yang dikirimkan dapat dibedakan pada saat proses transfer berlangsung; (d)Link. Link disini adalah cara komunikasi yang digunakan, pada komunikasi antar alat dan localhost yang digunakan adalah WiFi.

\section{HASIL DAN PEMBAHASAN}

\section{A. Pengujian Black Box}

Pengujian yang dilakukan adalah pengujian pada use case pada setiap bagian dari aplikasi di mana use case yang digunakan sebagai pengujian disini berjumlah 6 use case. 6 use case itu adalah use case login, use case user, use case ruangan, use case petugas, use case tugas, use case alat. Hasil yang diperlihatkan pada pengujian ini menunjukan 
respon aplikasi terhadap perintah yang dilakukan oleh user atau pengguna. Tabel 1 sampai Tabel 6 merupakan hasil dari pengujian terhadap setiap use case yang diujikan semua tabel di atas adalah respon dan kesimpulan yang bisa di ambil pada saat melakukan pengujian black box.

\section{B. Laporan Harian Otomatis}

Pada pengujian ini yaitu melakukan percobaan untuk malakukan pembuatan laporan di hari yang sudah ditentukan dapat dilihat pada Gambar 10 merupakan form pemilihan hari yang diinginkan untuk memasukan data kedalam laporan. Pada Gambar 12 merupakan hasil dari laporan otomatis yang berhasil dibuat dan pada Gambar 11 merupakan hasil yang dimiliki oleh aplikasi sebagai pembanding bahwa data yang disimpan sama.

\section{Komunikasi Client-Server}

Pengujian yang dilakukan adalah melakukan koneksi dari awal hingga data dapat diterima oleh aplikasi, hal pertama yang dilakukan adalah melakukan pengaturan nama WiFi dan password WiFi yang dimasukan pada mikrokontroler untuk mengatur ESP agar dapat langsung terkoneksi dengan WiFi yang sesuai dengan keinginan. Dapat dilihat pada Gambar 13 yang merupakan proses inisiasi koneksi terhadap WiFi, menginfokan IP address dan pada akhirnya menampilkan hasil dari data sensor pada lcd display. Setelah tahap client megirimkan data kepada server yang dapat dibuktikan pada Gambar 14, di mana pada Gambar 14 serial monitor arduino memperlihatkan proses pengiriman data dari mikrokontroler ke server dan pada Gambar 15, dapat dilihat bahwa tabel histori bertambah setelah mikrokontroler mengirimkan data ke server. Pada Gambar 16 merupakan hasil data yang ditampilkan di aplikasi sebagai pembanding bahwa database yang tersimpan dengan tampilan data yang ada pada aplikasi sama adanya.

\section{KESIMPULAN}

Pada penelitian ini dirancang sebuah sistem wireless monitoring dengan aplikasi berbasis web dan database medis. Berdasarkan hasil penelitian, multiple wireless monitoring berhasil diimplementasikan dalam sistem berbasis web dengan menggunakan PHP dan database yang dibuat di dalam MySQL. Dalam penelitian ini aplikasi berhasil mengimplementasikan tingkatan akses dalam aplikasi yang dibedakan menjadi dua tingkatan akses, dapat melakukan fungsinya sesuai dengan use case yang sudah diujikan dan dapat melakukan pembuatan laporan otomatis sesuai dengan hari yang ditentukan. Pada penelitian penelitian ini juga berhasil mengimplementasikan sistem pengiriman data secara wireless yang berbasis TCP/IP dan berhasil diterima oleh server lalu ditampilkan pada aplikasi. Pada penelitian penelitian ini juga telah berhasil membuat sebuah manajemen ruangan yang dibuat di dalam aplikasi dengan database MySQL, manajemen tersebut sudah memiliki tabel database yang berelasi dengan tabel database lain, maka hasil manajemen ruangan sudah terimplementasi dengan tepat.

\section{DAFTAR PUSTAKA}

[1] M. T. Vo, T. T. T. Nghi, V. S. Tran, L. Mai, and C. T. Le, "Wireless Sensor Network for Real Time Healthcare Monitoring: Network Design and Performance Evaluation Simulation," in IFMBE Proceedings, 2015, vol. 46, pp. 87-91.

[2] N. P. Windryani, "Nindithia Putri Windryani, " Comparison Analysis Between MQTT and HTTP Protocol in Iot Platform," $e$ Proceeding Eng., vol. 6, no. 2, 2019.

[3] P. Neves, M. Stachyra, and J. Rodrigues, "Application of Wireless Sensor Networks to Healthcare," J. Commun. Softw. Syst., vol. 4, no. 3, p. 181, 2008.

[4] H. Ahmed and A. Ali, "Wireless Sensor Network for Medical Applications," Iraqi J. Electr. Electron. Eng., vol. 11, no. 1, pp. 49-59, 2015.

[5] M. Elliott, "Critical Care: The Eight Vital Signs of Patient Monitoring," British journal of nursing, vol. 21 no 10, p. 621, 2012.," Br. J. Nurs., vol. 21, no. 10, p. 621, 2012.

[6] M. Elliott and A. Coventry, "Developing Residential Wireless Sensor," Br. J. Nurs., vol. 21, no. 10, pp. 621-625, May 2012.

[7] M. Husni, D. O. Siahaan, H. T. Ciptaningtyas, H. Studiawan, and Y. P. Aliarham, "Liquid volume monitoring based on ultrasonic sensor and Arduino microcontroller," in IOP Conference Series: Materials Science and Engineering, 2016, vol. 128, no. 1. 